\title{
Identification of the Mycobacterium tuberculosis Beijing lineage in Ecuador
}

\author{
Patricia Jiménez ${ }^{1,2}$, Karina Calvopiña ${ }^{1}$, Diana Herrera ${ }^{1}$, Carlos Rojas ${ }^{3}$, Laura Pérez-Lago 4,5,6, \\ Marcelo Grijalva ${ }^{1}$, Remedios Guna², Darío García-de Viedma ${ }^{4,5,6}$ \\ 1 Grupo de Investigación en Sanidad Animal y Humana, Departamento de Ciencias de la Vida y la Agricultura, \\ Universidad de las Fuerzas Armadas ESPE, Sangolquí, Ecuador \\ 2 Servicio de Microbiología, Hospital General Universitario de Valencia, Valencia, España \\ 3 Hospital "Alli Causai", Ambato, Ecuador \\ 4 Servicio de Microbiología Clínica y Enfermedades Infecciosas, Hospital General Universitario "Gregorio \\ Marañón", Madrid, España \\ 5 Instituto de Investigación Sanitaria "Gregorio Marañón", Madrid, España \\ 6 Centro de Investigación Biomédica en Red en Enfermedades respiratorias (CIBERES), Madrid, España
}

Introduction: Mycobacterium tuberculosis Beijing lineage isolates are considered to be especially virulent, transmissible and prone to acquire resistances. Beijing strains have been reported worldwide, but studies in Latin America are still scarce. The only multinational study performed in the region indicated a heterogeneous distribution for this lineage, which was absent in Chile, Colombia and Ecuador, although further studies found the lineage in Chile and Colombia.

Objective: To search for the presence of the Beijing lineage in Ecuador, the only country in the region where it remains unreported.

Materials and methods: We obtained a convenience sample (2006-2012) from two hospitals covering different populations. The isolates were genotyped using 24-MIRU-VNTR. Lineages were assigned by comparing their patterns to those in the MIRU-VNTRplus platform. Isolates belonging to the Beijing lineage were confirmed by allele-specific PCR.

Results: We identified the first Beijing isolate in Ecuador in an unexpected epidemiological scenario: A patient was infected in the Andean region, in a population with low mobility and far from the borders of the neighboring countries where Beijing strains had been previously reported.

Conclusion: This is the first report of the presence of the Beijing lineage in Ecuador in an unusual epidemiological context that deserves special attention.

Key words: Mycobacterium tuberculosis; tuberculosis; case reports; virulence; molecular epidemiology; Ecuador.

doi: http://dx.doi.org/10.7705/biomedica.v37i3.3450

\section{Detección de Mycobacterium tuberculosis, linaje Beijing, en Ecuador}

Introducción. Los aislamientos de Mycobacterium tuberculosis pertenecientes al linaje Beijing se consideran especialmente virulentos y transmisibles, y con mayor tendencia a la adquisición de resistencia. El linaje Beijing se ha reportado en todo el mundo; sin embargo, en Latinoamérica los estudios al respecto son más escasos. En el único estudio multinacional llevado a cabo en la región, se detectó una distribución heterogénea del linaje, y no se le encontró en Chile, Colombia y Ecuador, aunque en estudios nacionales posteriores se identificaron aislamientos en Chile y Colombia.

Objetivo. Rastrear la presencia del linaje Beijing de M. tuberculosis en Ecuador, único país en la región en el que aún no se reporta.

Materiales y métodos. Se analizó una muestra de conveniencia (2006-2012) en dos hospitales que atendían poblaciones diferentes. La genotipificación de los aislamientos de M. tuberculosis se hizo mediante la plataforma 24-MIRU-VNTR. La asignación de linajes se hizo mediante la comparación de los patrones genotípicos con los incluidos en la plataforma MIRU-VNTRplus, y aquellos pertenecientes al linaje Beijing fueron confirmados mediante reacción en cadena de la polimerasa específica de alelo.

\footnotetext{
Author's contributions:

Patricia Jiménez, Marcelo Grijalva, Remedios Guna, Darío García-de Viedma: study conception and design

Patricia Jiménez, Karina Calvopiña, Diana Herrera, Laura Pérez-Lago, Carlos Rojas: data collection, analysis and interpretation

Patricia Jiménez, Diana Herrera, Marcelo Grijalva, Darío García-de Viedma: article drafting

All authors revised and approved the final version before article submission.
} 
Resultados. Se detectó el primer aislamiento Beijing en Ecuador, en una circunstancia epidemiológica inesperada: un paciente de la región andina, proveniente de una comunidad con escasa movilidad y alejada de las fronteras con los países limítrofes, Perú y Colombia, en los que ya se han identificado aislamientos de $M$. tuberculosis pertenecientes al linaje Beijing.

Conclusiones. En este trabajo se reporta por primera vez la presencia del linaje Beijing de $M$. tuberculosis en Ecuador en un contexto epidemiológico inusual que merece especial atención.

Palabras clave: Mycobacterium tuberculosis, tuberculosis; informes de casos; virulencia; epidemiología molecular; Ecuador.

doi: http://dx.doi.org/10.7705/biomedica.v37i3.3450

Tuberculosis remains a major health concern in many countries and regions around the world. Data from the World Health Organization report an incidence of 54 cases per 100,000 inhabitants and a prevalence of 78 cases per 100,000 inhabitants in Ecuador (1).

The genotypic analysis of Mycobacterium tuberculosis isolates is a valuable aid in the study of transmission patterns of the disease. Genotyping techniques are useful for the identification of isolate clusters, and they provide researchers and clinicians with a better understanding of the transmission dynamics of this pathogen in different settings (2-4), allowing the differentiation of $M$. tuberculosis lineages as well. Some of them, such as the Beijing lineage, are considered to be more "successful" due to their virulence, transmissibility and acquisition of resistance $(5,6)$.

The Beijing family belongs to the East Asian lineage (lineage 2) and is considered to have emerged 6,600 years ago in northeast China, Korea and Japan. Migration movements have expanded the Beijing lineage around the world, with the highest prevalence currently found in Central Asia, the Black Sea area, Russia, Eastern Europe, and South Africa; however, in other areas, such as North America, its prevalence is low (7).

Many studies have focused on the analysis of the Beijing lineage in high prevalence areas, whereas studies in other areas of the world such as Latin America are still scarce. One of the few multinational studies in this region revealed a heterogeneous distribution of the Beijing lineage in the seven countries surveyed (8). In the four countries where it was

\footnotetext{
Corresponding author:

Patricia Jiménez, Grupo de Investigación en Sanidad Animal y Humana, Departamento de Ciencias de la Vida y la Agricultura, Universidad de las Fuerzas Armadas ESPE, Av. General Rumiñahui $s / n$., Sangolquí, Ecuador

Teléfono: (593) (02) 398 9400, extensión 2111

apjimenez@espe.edu.ec

Received: 19/07/16; accepted: 01/09/16
}

detected, its prevalence varied widely: Perú (5.9\%), Argentina (1.0\%), Brazil $(0.8 \%)$ and Paraguay $(0.6 \%)$. In the remaining three countries (Chile, Colombia and Ecuador) no Beijing isolates were identified. Subsequent nationwide studies, however, found Beijing lineage isolates in Colombia and Chile (9-11). Ecuador is the only country among those considered in the study where this lineage had not been reported yet.

The aim of our study was to look for the presence of the Beijing lineage in Ecuador based on regional epidemiology indicating its presence in Colombia and Perú, both bordering countries with Ecuador.

\section{Materials and methods}

\section{Clinical isolates}

We obtained a convenience sample of $28 \mathrm{M}$. tuberculosis isolates (2006-2012) from independent cases diagnosed in two teaching hospitals: The "Alli Causai" Hospital (Ambato, Tungurahua), which serves three provinces in the Ecuadorian Sierra region, and the "Carlos Andrade Marín" Hospital (Quito, Pichincha), a third level referral hospital.

\section{Microbiological procedures}

Following culture in Löwenstein-Jensen medium, M. tuberculosis isolates from pulmonary and extrapulmonary specimens were obtained (table 1). Culture and susceptibility testing were performed by experienced hospital laboratory staff at participating hospitals based on standard methods. Isolates in Löwenstein-Jensen medium were stored under standard conditions in hospital microbiology laboratories.

\section{Molecular procedures}

DNA extraction. Mycobacterium tuberculosis isolates were resuspended in Tris $\mathrm{HCl}$-EDTA (TE) and inactivated by boiling at $95^{\circ} \mathrm{C}$ for 45 minutes. DNA was purified following standard procedures (12).

Lineage identification by MIRU-VNTR analysis. The isolates were genotyped by MIRU-VNTR (24-loci) based on the simplex-PCR format followed by allelic 
Table 1. Geographic origin, type of specimen and susceptibility profiles for Mycobacterium tuberculosis isolates

\begin{tabular}{|c|c|c|c|c|c|c|c|}
\hline \multirow[t]{3}{*}{ Province } & \multicolumn{3}{|c|}{ Type of specimen } & \multicolumn{4}{|c|}{ Drug susceptibility } \\
\hline & \multirow[t]{2}{*}{ Respiratory } & \multirow[t]{2}{*}{ Extra-respiratory } & \multirow[t]{2}{*}{$N / D$} & \multicolumn{2}{|c|}{ Monoresistant } & \multirow{2}{*}{$\begin{array}{c}\text { Poliresistant } \\
\text { INH /SM }\end{array}$} & \multirow{2}{*}{$\begin{array}{c}\text { MDR } \\
\text { INH / RMP }\end{array}$} \\
\hline & & & & INH & RMP & & \\
\hline Bolívar & 1 & & & & & & \\
\hline Cotopaxi & 10 & 1 & & 2 & 1 & & \\
\hline Imbabura & 6 & & & & & & \\
\hline Pichincha & & 2 & & & & & \\
\hline Sucumbíos & 3 & & & & & 1 & 2 \\
\hline \multirow[t]{2}{*}{ Tungurahua } & 4 & & & & & & \\
\hline & & & 1 & & & & \\
\hline
\end{tabular}

INH: isoniazid; RMP: rifampicin; SM: streptomycin; N/D: no data

discrimination through agarose gel electrophoresis of the PCR products (12). Lineages for the isolates were assigned by comparing their MIRU-VNTR patterns with those in the MIRU-VNTR plus platform (http://www.miru-vntrplus.org/) $(13,14)$.

Analysis of lineage-specific SNP. Lineage identification from comparative analysis in the MIRU- VNTR plus platform was confirmed by the identification of lineage-specific SNP (15) using PCR and DNA sequencing. A lineage 2 isolate corresponded to the Beijing lineage, and the lineage was confirmed by Beijing allele-specific SNP [Rv2154724 (G526A)] PCR.

Phylogenetic analysis. MIRU-VNTR data were analyzed with the software packages available at www. miruvntrplus.org. A dendrogram based on these data was constructed using the Unweighted Pair Group Method with Arithmetic Mean (UPGMA). Isolates showing $100 \%$ identity were considered clustered.

\section{Ethical considerations}

The study was approved by the participating hospitals ethics committees.

\section{Results}

Our convenience sample included 28 isolates from six provinces in Ecuador. Six isolates were resistant, of which two were MDR (table 1). Twenty seven different VNTR genotypes were detected among the 28 MTB isolates genotyped. Two isolates from the Sucumbíos province (isolate 5 with INH-SM resistant phenotype and isolate 22 with INH-RMP resistant phenotype) were clustered into one separate cluster (figure 1). Lineages for the 28 isolates were determined based on the MIRUVNTR data. From these 28 isolates, 27 clustered to the MIRU-VNTRplus lineage 4 (Euro-American) entrances. The remaining isolate from the Cotopaxi province (isolate 49 , susceptible phenotype) grouped together with the lineage 2 entrances in the database. A second analysis based on the determination of lineage-specific SNP confirmed our MIRU-VNTR-based lineage assignment as lineage 2 Beijing for isolate 49 .

\section{Discussion}

The detection of certain $M$. tuberculosis lineages in different geographic areas should rely on consistent sampling to ensure population-based representativeness. Unfortunately, these features are not easily found in all settings, and convenience samples are thus used for these purposes. The Beijing lineage was absent in isolates from Chile, Ecuador and Colombia in a study conducted in several Latin American countries from 1997 to 2003 (8). However, it might have remained undetected due to limitations in the study's sample representativeness. Subsequent nation-wide studies of $M$. tuberculosis lineages demonstrated the Beijing lineage in Colombia (10), where the first case of multidrug-resistant tuberculosis by a rare Beijing strain was reported, and more recently, in Chile $(9,11)$, where Beijing strains were found in isolates from Santiago.

Ecuador remained the only country in Latin America among those included in the multinational study not reporting the Beijing lineage. Perú and Colombia, the two countries that share a border with Ecuador, had communicated the presence of this lineage with a high prevalence in certain settings $(16,17)$. This information led to the consideration that limitations in sample size could be responsible for the lack of detection of Beijing isolates in Ecuador. More importantly, the Beijing lineage was initially assumed to be associated with resistance, but this association has not been found on a global context. The Ecuadorian sample in the above multinational study included MDR isolates exclusively, and those included in the study corresponded to a single site 


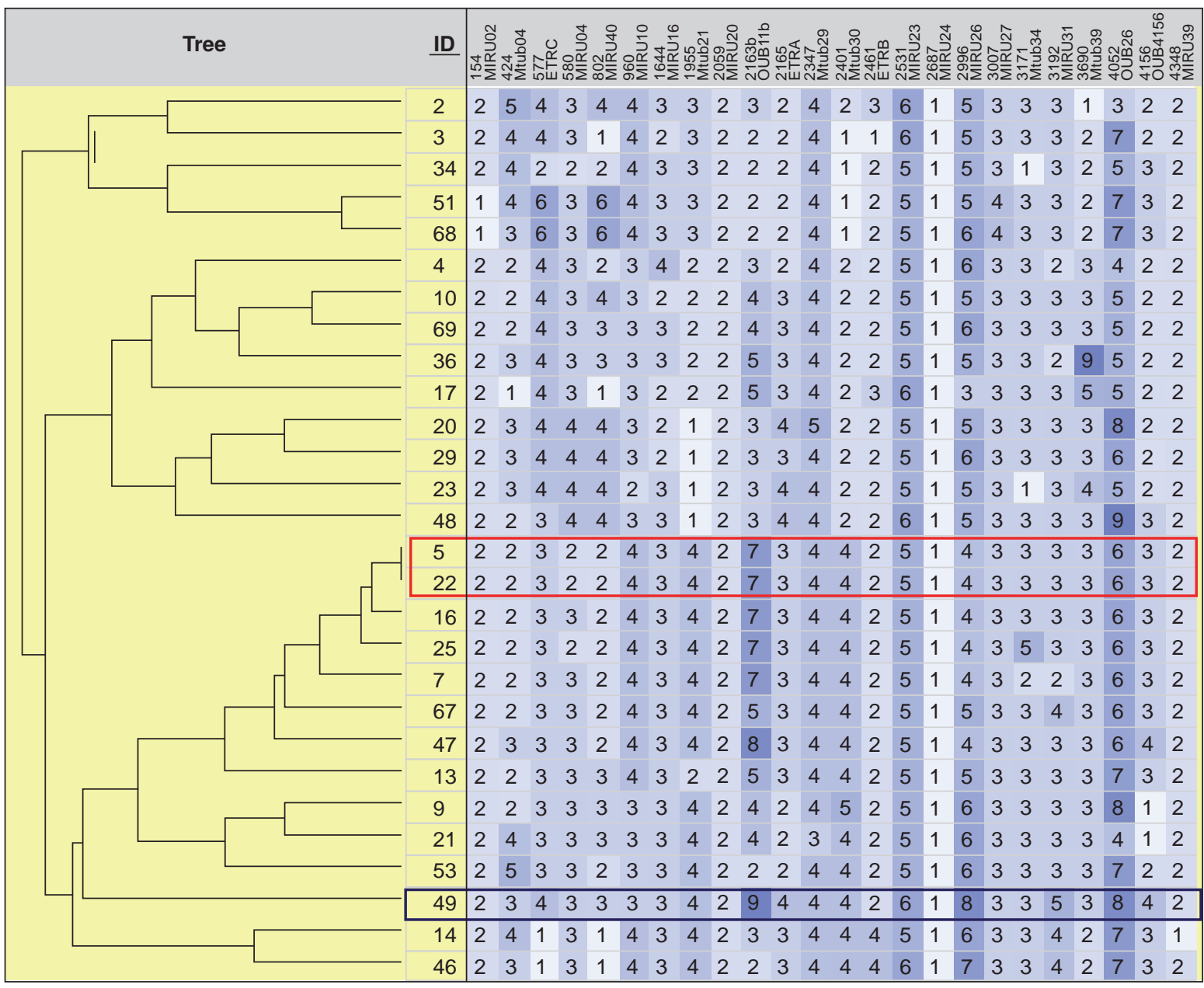

Figure 1. Phylogenetic tree and dendrogram based on the 24-locus-MIRU-VNTR analysis in MIRU-VNTRplus. The two clustered isolates from Sucumbíos province (isolates 5 and 22) and the Beijing isolate (isolate 49) are indicated within the red and blue boxes, respectively.

in Quito (18). In our opinion, including multidrugresistant tuberculosis isolates from only one site severely limited the study.

To minimize these potential biases, in this study we adopted a less restrictive approach. Isolates from six different Ecuadorian provinces, including susceptible isolates, were collected. As a result, we succeeded in identifying the Beijing lineage in the country. It is interesting to note that we were able to detect one isolate even in a small sample. However, more extensive studies are needed to know the true prevalence of the Beijing lineage in Ecuador.

Although the Beijing lineage has been reported in Perú and Colombia, isolates from Ecuadorian provinces near these countries do not belong to this lineage. Unexpectedly, the Beijing isolate corresponded to a patient from Cotopaxi, a nontouristic, agriculture-based Andean province. The population in this province has low mobility and little interaction with other regions. We were not able to obtain additional information from the patient infected with the Beijing strain. In this sense, it may be necessary to actively search for new cases that may reveal an unexpected epidemiological scenario for this lineage in Ecuador.

Only two isolates from our collection were clustered. It is interesting that they were both from the Sucumbíos province and they had a resistant phenotype. Although the number of isolates collected was low, transmission of resistant strains in this province deserves attention.

This is the first report of the presence of the Beijing lineage in Ecuador. The epidemiological context where it was detected is unexpected. Despite the importance of the identification of this lineage in the country, our study was based on the analysis of a 
limited collection from a convenience sample and, therefore, it should be expanded to help determine the prevalence of the Beijing lineage and clarify whether a peculiar epidemiological scenario is associated with its presence in Ecuador.

\section{Acknowledgements}

We thank Rachid Seqqat for proof reading the manuscript. Diana Herrera was supported by a grant from the Student Mobility Program of the Universidad de las Fuerzas Armadas, ESPE, Ecuador. We acknowledge Dr. Fernando Romero, Head of the Microbiology Laboratory of the "Carlos Andrade Marín" Hospital, for kindly supplying the clinical isolates.

\section{Conflicts of interest}

The authors report no conflicts of interest.

\section{Funding}

This research was funded by the Secretaría de Educación Superior, Ciencia, Tecnología e Innovación, SENESCYT, Ecuador, and by ISCIII FIS grant $(15 / 01554)$ and cofunded by ERDF (FEDER) Funds from the European Commission: "A way of making Europe". LP-L was supported by M. Servet CP15/00075.

\section{References}

1. World Health Organization. Global Tuberculosis Report 2015. Accessed on: August 18, 2016. Available at: http:// www.who.int/tb/publications/global_report/en/.

2. Barletta F, Otero L, de Jong B, Iwamoto T, Arikawa $\mathbf{K}$, Vander Stuyft $\mathbf{P}$, et al. Predominant Mycobacterium tuberculosis families and high rates of recent transmission among new cases are not associated with primary multidrug resistance in Lima, Perú. J Clin Microbiol. 2015;53:1854-63. http://dx.doi.org/.10.1128/JCM.03585-14

3. Millán-Lou M, Olle-Goig J, Tortola M, Martín C, Samper S. Mycobacterial diversity causing multi-and extensively drug-resistant tuberculosis in Djibouti, Horn of Africa. Int $\mathrm{J}$ Tuberc Lung Dis. 2016;20:150-3. http://dx.doi.org/10.5588/ ijtld.15.0268

4. Moonan P, Ghosh S, Oeltmann J, Kammerer J, Cowan L, Navin T. Using genotyping and geospatial scanning to estimate recent Mycobacterium tuberculosis transmission, United States. Emerg Infect Dis. 2012;18:458-65. http://dx. doi.org/10.3201/eid1803.111107

5. Luo T, Comas I, Luo D, Lu B, Wu J, Wei L, et al. Southern East Asian origin and coexpansion of Mycobacterium tuberculosis Beijing family with Han Chinese. Proc Natl Acad Sci USA. 2015;112:8136-41. http://dx.doi.org/10.1073/ pnas. 1424063112

6. Wada T, Iwamoto T, Hase A, Maeda S. Scanning of genetic diversity of evolutionarily sequential Mycobacterium tuberculosis Beijing family strains based on genome wide analysis. Infect Genet Evol. 2012;12:1392-6. http://dx.doi. org/10.1016/j.meegid.2012.04.029
7. Merker M, Blin C, Mona S, Duforet-Frebourg N, Lecher $\mathrm{S}$, Willery $\mathrm{E}$, et al. Evolutionary history and global spread of the Mycobacterium tuberculosis Beijing Lineage. Nat Genet. 2015;47:242-9. http://dx.doi.org/10.1038/ng.3195

8. Ritacco V, López B, Cafrune P, Ferrazoli L, Suffys P, Candia N, et al. Mycobacterium tuberculosis strains of the Beijing genotype are rarely observed in tuberculosis patients in South America. Mem Inst Oswaldo Cruz. 2008;103:48992. http://dx.doi.org/10.1590/S0074-02762008000500014

9. Meza P, Balcells M, Miranda C, Cifuentes M, Wozniak A, García P. Presence of Bejing genotype among Mycobacterium tuberculosis strains in two centres of the Región Metropolitana of Chile. Rev Chil Infectol. 2014;31:21-7. http://dx.doi.org/10.4067/S0716-10182014000100003

10. Murcia M, Manotas M, Jiménez $\mathbf{Y}$, Hernández J, Cortés M, López L, et al. First case of multidrug-resistant tuberculosis caused by a rare "Beijing-like" genotype of Mycobacterium tuberculosis in Bogotá, Colombia. Infect Genet Evol. 2010;10:678-81. http://dx.doi.org/10.1016/j. meegid.2010.03.010

11. Lagos J, Couvin D, Arata L, Tognarelli J, Aguayo C, Leiva T, et al. Analysis of Mycobacterium tuberculosis genotypic lineage distribution in Chile and neighboring countries. PLoS One. 2016;12:11:e0160434. http://dx.doi. org/10.1371/journal.pone.0160434

12. Supply P, Allix C, Lesjean S, Cardoso-Oelemann $\mathrm{M}$, Rusch-Gerdes S, Willery $\mathrm{E}$, et al. Proposal for standardization of optimized mycobacterial interspersed repetitive unit-variable-number tandem repeat typing of Mycobacterium tuberculosis. J Clin Microbiol. 2006;44:4498510. http://dx.doi.org/10.1128/JCM.01392-06

13. Allix-Beguec C, Harmsen D, Weniger T, Supply P, Niemann S. Evaluation and strategy for use of MIRUVNTRplus, a multifunctional database for online analysis of genotyping data and phylogenetic identification of Mycobacterium tuberculosis complex isolates. J Clin Microbiol. 2008;46:2692-9. http://dx .doi.org/10.1128/JCM.00540-08

14. Weniger T, Krawczyk J, Supply P, Niemann S, Harmsen D. MIRU-VNTRplus: A web tool for polyphasic genotyping of Mycobacterium tuberculosis complex bacteria. Nucleic Acids Res. 2010;38:W326-31. http://dx.doi.org/10.1093/ nar/gkq351

15. Stucki D, Malla B, Hostettler S, Huna T, Feldmann J, Yeboah-Manu D. Two new rapid SNP-typing methods for classifying Mycobacterium tuberculosis complex into the main phylogenetic lineages. PLoS One. 2012;7:e41253. http://dx.doi.org/10.1371/journal.pone.0041253

16. Iwamoto T, Grandjean L, Arikawa K, Nakanishi N, Caviedes L, Coronel J. Genetic diversity and transmission characteristics of Beijing family strains of Mycobacterium tuberculosis in Perú. PLoS One. 2012;7:e49651. http://dx. doi.org/10.1371/journal.pone.0049651

17. Nieto L, Ferro B, Villegas S, Mehaffy C, Forero L, Moreira C, et al. Characterization of extensively drug-resistant tuberculosis cases from Valle del Cauca, Colombia. J Clin Microbiol. 2012;50:4185-7. http://dx.doi.org/10.1128/JCM. 01946-12

18. Glynn J, Whiteley J, Bifani P, Kremer K, van Soolingen D. Worldwide occurrence of Beijing/W strains of Mycobacterium tuberculosis: A systematic review. Emerg Infect Dis. 2002;8:843-9. http://dx.doi.org/10.3201/eid0805.020002 